\title{
A coleta de lixo domiciliar na cidade do Rio de Janeiro: um estudo de caso baseado na percepção do trabalhador
}

\author{
Home garbage collecting in the city of Rio \\ de Janeiro: a case study discloses the sanitation \\ workers point of view
}

Marta Pimenta Velloso 1

Jorge de Campos Valadares 2

Elizabeth Moreira dos Santos 3

${ }^{1}$ Centro de Saúde Escola Germano Sinval Faria, ENS, Fiocruz.

2 Departamento de Saneamento e Saúde Ambiental, ENS, Fiocruz.

3 Departamento de

Grandes Endemias,

ENS, Fiocruz.
Abstract This article discloses the sanitation workers point of view on specific topics such as health risks and unsafe conditions met during home garbage collecting process. Located in Rio Comprido neighbourhood, the choosen workplace unit was the East Cleaning Management District (Gerência de Limpeza Leste, LGL-3), branch of Rio's Street Cleaning Municipal Company (COMLURB). The method employed in this survey consisted of tape recorded single interviews and video recording sanitation workers daily operations, with written notes and comments by the researchers. Instead of being considered merely "garbage carriers", the sanitation workers are now asking for the basic improvements in order to make this particular acitivity more suitable to meet the best of their human expectations. Besides, the sanitation workers are claiming the company implementation of new services like full health coverage and professional training courses. According to sanitation workers, the disregard and professional underrating shown both by the company, and the general population, are their main sources of concern.

Key words Workers' Health; Occupational Health; Occupational Accidents; Accidents; Workplace
Resumo Este artigo analisa, baseando-se na visão do trabalhador, as condições de riscos e segurança encontradas no processo de trabalho da coleta de lixo domiciliar. A unidade especifica de estudo foi a Gerência de Limpeza Leste (LGL-3), situada no bairro do Rio Comprido, da Companhia Municipal de Limpeza Urbana do Rio de Janeiro (COMLURB). O instrumento utilizado na pesquisa foi a entrevista individual e gravada, sendo enriquecida pela observação do pesquisador. O trabalhador percebe que, para melhorar suas condições de trabalho, torna-se necessária uma adaptação do trabalho ao homem, ou seja, não usar o seu próprio corpo apenas como instrumento de carregar o lixo. Além disso, esses trabalhadores demandam a implantação de novos serviços na empresa, tais como: serviços de atenção integral à Saúde e cursos de treinamento para o serviço. Um dos grandes problemas identificados pelos trabalhadores é a sua falta de valorização profissional, tanto pela empresa, quanto pela população.

Palavras-chave Saúde do Trabalhador; Saúde Ocupacional; Acidentes de Trabalho; Acidentes; Local de Trabalho 


\section{Introdução}

Como a palavra lixo representa o resíduo sólido desprezado pela população, os profissionais encarregados da coleta desses resíduos são chamados genericamente de "lixeiros" ou "garis"1. O núcleo simbólico depreciativo associado à denominação dada à referida ocupação se origina dos próprios lixeiros, de suas condições econômicas, sociais e de trabalho adversas, que dinamicamente interagem com a imagem da população sobre eles.

De um lado, situações concretas de trabalho em que esses trabalhadores vêem-se obrigados diariamente a ter que lidar com uma realidade tão universalmente abjeta, de outro, os trabalhadores sequer recebem salários condignos, socialmente eqüitativos até mesmo com outras categorias pertencentes ao setor terciário, no qual se inserem. Assim, não existem quaisquer condições em que a negociação social de prestígio profissional possa superar ambas as fontes de "mal-estar" psíquico, em relação à vida e à identidade profissional dos "lixeiros".

O processo de trabalho de coleta de lixo domiciliar é constituído de uma tecnologia precária, praticamente manual, onde o corpo do trabalhador transforma-se em instrumento de carregar o lixo.

A vivência concreta dessa situação, isto é, o identificar-se com um instrumento de transporte de dejetos, implica experiência de determinadas condições desagradáveis do estado psíquico, sobretudo na vida emocional dos sujeitos. Para alguma mudança nessa realidade é necessária uma consciência aguda da precariedade humana, daquilo que é sempre falho, com a qual o sujeito deve enfrentar o "real", o "natural", ou seja, seu próprio corpo como fonte de vida e, ao mesmo tempo, como contínuo resto da atividade de viver, que retorna sempre insatisfeito. Essa precariedade provém da supressão necessária de um sentimento oposto, daquilo que situaria o corpo e a vida como sempre "completos" e fonte inesgotável de gozo e que deve ser afastado para o apare-

${ }^{1}$ No início do século, os serviços de limpeza urbana foram entregues à iniciativa privada, quando então os "Irmãos Garys" assumiram a Companhia Industrial do Rio de Janeiro, por autorização do Governo Municipal para desempenhar os serviços de coleta, transporte e destino do lixo. Desde então, os trabalhadores de coleta de lixo, passaram a ser denominados pelo nome genérico de seus patrões "garis". cimento do "lugar do outro", e que a psicanálise nomeou como recalcado. A aceitação da falha, necessária para o processo da cultura, é sempre provisória e dura até a realização de algum prazer. Antes do aparecimento de uma revolta, do acionamento do sistema motor, ou do silêncio re-sentido, um pensamento e uma ação modificadora devem ser viabilizados, na direção de melhora em relação ao mal-estar. Voltaremos ao tema.

A coleta seletiva que separa o lixo reciclável (vidro, agulhas, latas, madeiras) do restante, além de evitar acidentes como cortes e ferimentos, pode contribuir para transformar a visão estigmatizante desta profissão. O lixo, visto como resíduo desprezado,passa a ser considerado matéria-prima, podendo ser transformado e reutilizado pela população.

Essa solução de racionalidade positiva enfrenta, como obstáculos, concepções societárias que dificilmente associam a imagem do lixo (objeto desprezado) como material que pode ser retransformado e reinserido em um novo ciclo produtivo, e raramente incorporam informações sobre a relação coleta de lixo e saúde do trabalhador.

É nesse contexto que nasce o presente estudo o qual visa, através da percepção do trabalhador, registrar algumas de suas condições de segurança e riscos à saúde provenientes deste processo de trabalho.

\section{Metodologia}

O presente, realizado entre junho de 1994 e janeiro de 1995, envolveu a percepção do trabalhador, enriquecida pela observação participante do pesquisador.

Como unidade de estudo, escolheu-se o trabalhador da Gerência de Limpeza Leste (LGL-3) da Companhia Municipal de Limpeza Urbana do Rio de Janeiro (COMLURB). A COMLURB é uma empresa municipal, subordinada à Prefeitura, sendo responsável pela coleta, transporte e destino do lixo.

A empresa possui 26 gerências de limpeza, localizadas nos diversos bairros do município, cada uma delas sendo responsável pela sua respectiva área de abrangência. Conta com um total de 1400 coletores de lixo domiciliar. $\mathrm{Na}$ gerência estudada, situada no bairro do Rio Comprido, havia 29 trabalhadores, mas, por motivos operacionais, somente foi possível entrevistar 24 deles. Assim, o grupo sob estudo 
foi composto por esses indivíduos, todos do sexo masculino, com idades entre 25 e 56 anos (média de 37 anos) e alfabetizados. Esses trabalhadores possuíam vínculo empregatício com a empresa, sendo regidos pelo regime CLT, e todos aceitaram participar voluntariamente da pesquisa.

Como instrumento de Coleta de Dados, utilizou-se a entrevista semi-estruturada (Velloso, 1995), abrangendo a percepção do trabalhador sobre as causas dos acidentes relacionados ao seu trabalho, satisfação no trabalho e sugestões para melhoria das suas condições de trabalho.

A entrevista foi individual e os dados obtidos foram gravados, sendo as falas do trabalhador interpretadas, conforme estudo de caso descrito em Becker (1994), onde o autor descreve a análise de dados, baseada na observação participante do pesquisador.

\section{Causas de acidentes relacionados ao trabalho}

Os trabalhadores polarizam sua percepção das razões para se acidentarem. De um lado, cerca de um terço dos trabalhadores, identificam o processo de trabalho como responsável pelos agravos por eles sofridos em sua atividade, podendo aí se eximir até mesmo de sugestões. De outro, se auto-responsabilizam por esses eventos, exigindo, em certas circunstâncias, uma perfeição, uma completeza imaginária.

Constatou-se que o maior percentual de acidentes foi por eles atribuído às causas inerentes ao processo de trabalho, traduzidas co- mo: processo de trabalho em si $(33,3 \%$, dos trabalhadores), e falta de medidas preventivas (equipamento de proteção individual e treinamento) (Tabela 1). Somando-se a estes aqueles trabalhadores que identificam os acidentes como resultado da falta de treinamento para o serviço $(4,2 \%)$ e devido ao processo de trabalho associado à falta de equipamentos de proteção individual (20,8\%), verificase que $58,3 \%$ dos trabalhadores relacionam os acidentes ao processo de trabalho.

Concomitantemente, parece evidente que o próprio trabalhador se auto-identifica como responsável pelos acidentes que sofre. Agregando-se as categorias: descuido do trabalhador $(12,5 \%)$, ritmo acelerado do trabalhador $(8,3 \%)$, ingestão de bebidas alcoólicas $(8,3 \%)$, descuido do trabalhador e bebida $(4,2 \%)$, constata-se que $33,3 \%$ dos trabalhadores se julgam responsáveis pelos acidentes. É interessante notar que $8,4 \%$ dos trabalhadores dividem sua responsabilidade com a da empresa, na percepção de causalidade dos acidentes. Desses, $(4,2 \%)$ consideram que os acidentes ocorrem devido ao processo de trabalho e $4,2 \%$ à falta de EPI (Equipamento de Proteção Individual).

Essa polarização, claramente, se evidencia através da fala do trabalhador.

“...O latão pesado de 200 litros, que a COMLURB já proibiu, às vezes força e tem que ter quatro pessoas para levantar. A falta de segurança, porque viajamos pendurados com risco de cair e esse negócio de trabalhar em morro, chão esburacado, com peso de tudo quanto é espécie (vidro, lata que corta e machuca). A falta

Tabela 1

Percepção dos 24 coletores de lixo domiciliar estudados da Companhia Municipal de Limpeza Urbana do Rio de Janeiro, em relação às principais causas atribuídas aos acidentes ocorridos durante o trabalho de coleta, jul/94.

\begin{tabular}{lrr}
\hline Causas & $\mathbf{n}$ & $\%$ \\
\hline Inerentes ao processo de trabalho & 8 & 33,3 \\
Devido ao processo de trabalho e falta de EPI & 5 & 20,8 \\
Descuido do trabalhador & 3 & 12,5 \\
Ritmo acelerado do trabalhador & 2 & 8,3 \\
Ingestão de bebidas alcoólicas & 2 & 8,3 \\
Falta de treinamento para o serviço & 1 & 4,2 \\
Inerentes ao processo de trabalho e ao descuido do trabalhador & 1 & 4,2 \\
Descuido do trabalhador e bebida & 1 & 4,2 \\
Descuido do trabalhador e falta de EPI & 1 & 4,2 \\
Total & 24 & 100,0 \\
\hline
\end{tabular}


de segurança é atribuída à própria Companhia, porque deveria ter um meio de trabalho, onde o trabalhador não colocasse totalmente o corpo como um objeto de carregar o lixo: Usasse uma coisa fora do corpo..."

"...Por causa do caminhão, às vezes uma luva furada, uma bota saltando a sola. Você nunca está esperando que aquele furinho da luva vai pegar uma borda de latão. Você pede a Deus que não aconteça. Uma vez, em Botafogo, o caminhão passou por cima da cabeça de um colega. Ele vinha andando atrás do caminhão e escorregou. O caminhão passou em cima da cabeça dele..."

A culpabilização de si próprio também é explicitada claramente nos depoimentos dos trabalhadores.

"... O que acontece mais com certos colegas é falta de atenção, porque se eles tiverem atenção muitos acidentes podem ser evitados. Eu tenho quatorze anos de companhia e nunca sofri um acidente por descuido de minha parte. O primeiro alerta para o próximo: tem que pegar a bolsa com atenção. As pessoas quebram um vidro, botam na bolsa de plástico, e fura a bolsa. Desde o momento que fura, bate na perna..."

“...Eu nunca fiquei inseguro trabalhei até correndo. O que leva as pessoas se acidentarem é a pessoa ficar descuidada. O serviço é perigoso por causa do caminhão, tem que estar com atenção..."

“... Falta de atenção do cara. A gente, que trabalha na rua, tem que ter muita atenção..."

Reitera-se que essa culpabilização é poucas vezes absoluta. O trabalhador relativiza, "o serviço é perigoso", deixando perceber que tem clareza das condições precárias de seu trabalho.

"... Muito acidente, o que causa é falta de atenção do trabalhador, eu passei a observar isso, depois que fiz um curso no SENAI. Eu trabalho em morro, com o carro vazando óleo, o lugar para você segurar cheio de óleo...”

Da mesma forma, nesse processo de relativização, o trabalhador se localiza na ansiedade originada pelo trabalho, na desestruturação de suas relações psico-afetivas com seus colegas de trabalho e na ansiedade gerada pela sua luta de sobrevivência e associações com seus problemas.

“... Muito nervosismo dentro do serviço. A gente sai de casa com um pensamento, mas, quando a gente sobe no caminhão modifica tudo. O cara fica apreensivo porque está trabalhando de tênis e muita gente falando com ele. $O$ barulho atrapalha, o psicológico da gente fi- ca abalado e aí vem a insegurança da gente ali. A cabine é para o motorista, porque tem diferença do motorista para o gari, tem a discriminação e muitos deles se acham donos daquela cabine. Quando está sol ou quando está chovendo, o gari vai atrás do caminhão para evitar conflito com o motorista, mesmo que ele ofereça a gente não vai, porque nós estamos sujos e ele, por estar "limpinho" acha que não devíamos estar ali...”

A interação entre as características do processo de trabalho e as condiçõoes específicas do ambiente, sejam elas variações de tempo ou condições referentes à topografia da cidade do Rio de Janeiro, também estão claramente identificadas pelo trabalhador como desencadeadoras de acidente.

“... Em tempo de chuva, o estribo fica escorregando. Acho que devia ter um lugar para o gari viajar dentro. O carro particular tem uma parte no meio para o gari sentar, quando vai embora. Só trabalha na traseira, quando está coletando o lixo, nenhum carro da COMLURB tem isso..."

“... A gente trabalha no sol, na chuva e não pode parar. O corpo da gente sente à beça a diferença..."

Esta desestruturação e o sofrimento mental do trabalhador o fazem duplamente vulnerável. De um lado, a consciência do risco no trabalho, a impossibilidade de romper a precariedade das interações trabalho e ambiente em que a sua própria "sujeira" é fator decisivo. Do outro, a necessidade de descarregar frustrações e a agressividade podem induzir o trabalhador a recorrer a bebidas alcoólicas, como forma de aliviar a tensão interna. Dupla vulnerabilidade porque se trata de um alívio arriscado, agravante da culpa.

“... Os acidentes estão quase todos envolvidos com a bebida. O trabalho é feito na rua. Se o cara fizer o trabalho conforme deve ser feito (devagar, botar atenção no serviço) não acontece nada..."

“... Por causa do próprio trabalho tá certo. Mas acontece muitos acidentes com nós que trabalha na rua, porque cada um gosta de tomar um "gorozinho", às vezes, o cara toma um "pouquinho" demais, aí já não é problema da Companhia, já é problema do trabalhador..." 


\section{Mudanças capazes de melhorar as condições de trabalho}

Coerentemente com a racionalidade que apóia a percepção de causas dos acidentes, foi unânime entre os entrevistados a resposta de que a melhoria das condições de trabalho só aconteceria a partir da própria empresa. Esta, segundo eles, não estaria propiciando condições adequadas de trabalho. Na fala dos entrevistados, evidenciou-se que se houve aprimoramento tecnológico e operacional, estes não se fizeram acompanhar de uma melhora nas condições de trabalho: contratação de carros de empresa particular, mas salários atrasados; usina de reciclagem, mas manutenção precária dos veículos coletores de lixo.

$\mathrm{O}$ trabalhador percebe que, apesar do investimento da empresa em desenvolvimento tecnológico e operacional, seus instrumentos de trabalho estão em processo de deterioração.

“... A COMLURB tem tudo para ser uma ótima Companhia. O lixo é muito rico, é uma Companhia que nunca vai entrar na falência, entra se os outros quiser. Porque o lixo nunca acaba e a matéria-prima dela é o lixo. Ainda mais agora com essas Usinas que eles criaram e que estão reciclando direto e a frota da companhia está no estado que está. Tem carro aí que dá pena, porque não tem manutenção..."

As empresas particulares contratadas pela COMLURB (para realizar a coleta do lixo em alguns bairros da cidade) são identificadas pelo trabalhador como responsáveis, pelos efeitos prejudiciais sobre suas condições de trabalho, tais como: atraso no pagamento do salário e situação precária dos veículos coletores de lixo.

“... Esse prefeito não quer botar carro novo para trabalhar. Não tem carro, ele inventou esse negócio de empresa particular e esses carros que estão pagando uma fortuna e a gente recebe dia 7 , porque tem que pagar as duas empresas, então fica feio o negócio. Nós não temos carro, está tudo quebrado, novo é a casca, mas por dentro..."

Os trabalhadores percebem, além da necessidade de medidas preventivas, a necessidade de mudanças relacionadas à adaptação do trabalho ao homem.

"... Sugestões? A melhor coisa que eles tinham que fazer é dar material que a gente precisa para trabalhar. A roupa, o sapato, a luva e capa. Além desses, a gente não pode mais usar equi- pamento nenhum, por causa dos movimentos que a gente faz. Eles não dão capa para a gente trabalhar, se estiver chovendo a gente trabalha embaixo de chuva..."

"... Não pegar desses latões grandões (200 litros) e que não socassem bastante o lixo, para não ficar tão pesado, ainda mais quando chove ele enche de água e fica mais pesado..."

O grupo de trabalhadores evidencia a necessidade de medidas preventivas especiais e da existência de um serviço de atenção à saúde do trabalhador, que contemple não só a atenção médica integral, como também treinamento em primeiros socorros relacionados à exposição ao risco. O trabalhador percebe que os cuidados da empresa estão voltados somente à limpeza, negligenciando a sua saúde.

“... Equipamentos, materiais de forma adequada para o nosso uso. Eu trabalho na coleta hospitalar, tem que ter uma roupa especial; lu$v a$, porque a gente entra em certos hospitais que existe muito tipo de infecção. Por isso estamos tentando para ver se consegue algum dia, alguém para zelar pela gente. Até agora, trabalhamos com uniforme comum e chega em casa tem que separar aquela roupa. A luva fica separada lá e a roupa a gente leva para lavar em casa. Minha companheira já furou até o dedo num grampo que estava dentro da minha roupa..."

"... Assistência médica melhor para os funcionários, se a gente não tiver bem de saúde não vai adiantar a gente fazer um certo tipo de esforço, que a gente não vai conseguir. Tem muito colega meu que trabalha na COMLURB, que não agüenta esse tipo de serviço de coleta e eles continuam aí..."

"... Primeiros socorros, mais conhecimento ao gari, o cara só sabe que vai pegar o lixo. Tem gente, que trabalha com lixo contaminado..."

Durante as observações do processo de trabalho, verificou-se que os trabalhadores, nem sempre trajavam uniforme completo, ou seja, apresentavam-se sem botas, sem luvas, sem boné, com calça e blusa em estados precários. $\mathrm{Na}$ entrevista, alguns trabalhadores, alegaram que o uso freqüente das luvas causava dermatite de contato, além de dificultar o serviço, devido à perda de tato.

Outro ponto enfatizado pelo trabalhador é a sua falta de participação no poder decisório da empresa, com relação ao seu trabalho. Simultaneamente, as falas refletem o sentimento de desamparo do trabalhador, em relação aos seus direitos, no âmbito da empresa. 
“... A firma tinha que ouvir mais a gente sobre os problemas que acontecem na rua. Eles só punem a gente, nunca conversam para saber a nossa razão. 'Tão sempre dando razão à população e não escutam a gente. Poxa! Eu queria estar trabalhando para alguém que se preocupa com o meu serviço, sabendo que estou na rua, estou correndo risco lá. Um dia o caminhão estava ruim e eu não consegui falar pelo telefone porque estava ocupado, quem atendeu foi a secretária dele e não deu o recado. Eles só querem cobrar de você. Está tudo 'certinho', está tudo bom. Eu não me lembro de alguém elogiar alguém no trabalho. Me lembro sim elogiarem uma guarnição lá na Gávea. Na COMLURB eles não elogiam, a gente é igual cachorro..."

\section{Satisfação no trabalho}

Segundo as falas dos coletores de lixo, tornou-se possível categorizar dois grupos de trabalhadores: o primeiro relacionado à categoria dos que se dizem satisfeitos (75\%) e o segundo referente àqueles que se sentem insatisfeitos $(25 \%)$.

A categoria de trabalhadores que se diz " $s a$ tisfeita" é bastante questionável, já que a maioria desses mostrou-se ressentida com a empresa e/ou com a discriminação da população diante do seu trabalho. Além disso, a minoria "totalmente" satisfeita respondeu as perguntas sem entusiasmo e com certo temor.

Os depoimentos obtidos tornam evidente que a categoria dos trabalhadores, que se dizem "satisfeitos", valoriza seu trabalho, porque o mesmo representa sua sobrevivência.

“... Sinto satisfeito, ele garante o sustento da minha família. Quanto a isso, tudo bem. Meu problema está nesses acidentes..."

"... Estou satisfeito, porque o que tenho épelo trabalho. Minha casa, estou construindo outra por cima, graças à Deus..."

"... Fui criado na roça e não tive estudo, para mim é um bom trabalho..."

Apesar de "satisfeitos", essa categoria de trabalhadores ressente-se da discriminação da população em relação ao seu trabalho.

"... Eles discriminam, eles olham para o gari como eles olham um "porco". Eles não sabem que o gari é um homem ou uma mulher igual a eles..."

"... Uma vez um vizinho meu que passava na minha porta e bebia na minha barraca, me viu trabalhando num carro, eu falei com ele e ele não respondeu..."
"... As pessoas têm nojo da gente, acham que a gente tem uma doença contagiosa..."

"... A gente entra no ônibus, o pessoal se afasta da gente..."

A proximidade com o lixo e com o lixeiro, que é imediatamente ao lixo associado, passa a ser uma situação indesejável. A identificação se refere a proximidades que são denegadas. A posição ereta afastou o homem de odores das fezes e da urina, por onde se orientava no território, em busca de contatos com parceiros e esse afastamento o levou ao que Freud denominou de recalcamento orgânico. O lixo permanece na vida emocional do sujeito, como algo estranho (Freud, 1918) e, por isso, inquietante, inútil ou daninho e, assim sendo, deve ser excluído (Freud, 1925). O lixo, nessa condição, lembra tudo o que é "resto" e, com o percurso do seu destino, acompanhamos inconscientemente o destino do nosso próprio corpo, quer como imagem de fragmentação, quer como representação de decomposição final.

Esses trabalhadores ressentem-se da desvalorização da empresa, seja através da falta de participação no poder de decisão, em relação ao seu trabalho, ou mediante à negligência da mesma, no que diz respeito à sua saúde, ao baixo salário e à falta de incentivos e/ou gratificação pessoal que recebem para desempenhar um serviço altamente penoso.

"... Muito gari sabe, mais que um chefe, do que um fiscal. Às vezes ele tem uma sugestão melhor, mas não é válido..."

“... A Companhia acha que está tudo bom, ela quer a cidade limpa. O esforço que a gente faz, o tempo que a gente vai gastar, a barra que a gente vai ter que correr, para ela tanto faz..."

"... Eu saio para rua, faço a minha tarefa, acabo a minha, ajudo a do meu colega e não tenho uma compensação..."

"... A pessoa para eles só tem valor se tiver ali, na função. Agora se depender da gente sofrer um acidente ou ter que afastar do serviço, eles parecem que abandonam a pessoa de uma vez por todas..."

"... Me lembro que a gente fez uma greve aí e a cidade ficou suja à beça. O prefeito deu um cansaço na gente e gastando o dinheiro em bobeira, a Lagoa Rodrigo de Freitas já é área de lazer..."

Essa categoria, além de ressentida com a desvalorização pela empresa, sente insegurança devido à contratação de quatro empresas particulares (Cavo, Enterpa, SPL e FIAT) pe- 
la COMLURB, por ocasião da última greve dos coletores de lixo em Abril de 1994.

“... Eu e meus colegas nos dedicamos ao trabalho, mas não sabemos se estamos agradando. Eles contrataram esses carros particulares e falaram que esses caras estão fazendo um bom serviço..."

\section{Discussão}

O processo de trabalho não é visto isolado do ambiente onde o trabalho é desenvolvido. Sistematicamente o trabalhador integra o processo de trabalho às condições específicas da cidade do Rio de Janeiro, tais como: a topografia, o tráfego e a própria violência do cotidiano da cidade.

Segundo os autores (Cohn et al 1985 \& Faleiros, 1992), o Estado atribui como principais causas dos acidentes de trabalho, àquelas referentes aos atos inseguros do trabalhador, e as campanhas destinadas à prevenção de acidentes são dirigidas somente aos trabalhadores, excluindo-se os patrões. No grupo estudado, a autoculpabilização é também um dos fatores identificados como causadores de acidentes. Pode-se então assumir, que a culpa sobre o ato inseguro transmitida pelo Estado, através dos seus órgãos oficiais, induz ao trabalhador uma visão fragmentada das causas referentes aos acidentes ocorridos.

Isto pode ser entendido, considerando a orientação fornecida pela COMLURB aos coletores de lixo, quando a chefia enfatiza a necessidade de usar equipamentos de proteção individual (EPIS) e de não ingerir bebidas alcoólicas para evitar acidentes. Essas recomendações representam quase uma ameaça ao trabalhador, dada a natureza enfática de sua presença nos treinamentos e folhetos de orientação da empresa, enquanto outras recomendações de igual ou maior importância, nem sempre são transmitidas, como por exemplo, medidas preventivas contra doenças infecciosas (dengue, febre amarela, tétano, hepatite, cólera), posturas adequadas para levantar e transportar pesos, cuidados com materiais que oferecem risco (lata, garrafa, vidro, seringa, substância inflamável) e cuidados com infecções (da pele, dos olhos, dos aparelhos digestivo e respiratório).

Vários autores (Pereira, 1978; Robazzi, 1984; Ilário, 1989; Betancourt, 1993) relatam a problemática dos coletores de lixo consumi- rem álcool durante o serviço. A recomendação freqüente da COMLURB aos trabalhadores para "não ingerirem bebidas alcoólicas durante o serviço" e a autoculpabilização desses trabalhadores pelos acidentes atribuídos ao consumo das mesmas sugere que os coletores de lixo estudados consomem álcool com freqüência, inclusive durante a jornada de trabalho. A esses trabalhadores não é permitido nenhum espaço seja decisório seja participativo e terapêutico para elaborarem a ambigüidade que vivenciam.

O sentimento de impotência do trabalhador para transformar suas condições de vida e a insatisfação referente ao seu trabalho, podem também estar relacionados à ingestão de álcool referida. Estes profissionais se dizem "satisfeitos" com a profissão pelo fato de a mesma representar sua sobrevivência. No entanto, a insatisfação dessa categoria pode ser evidenciada, seja através da sociedade que lhe confere a identidade de "porco" e de "infectado capaz de contagiar" ou através da própria empresa. Esta deseja ver a cidade limpa, mas negligencia não só os riscos físicos, químicos e biológicos aos quais o trabalhador fica exposto como também a sobrecarga psíquica a que estão sujeitos pela sua identidade social.

Os trabalhadores estudados percebem, como mudanças capazes para melhoria das suas condições de trabalho, diversos fatores, tais como: distribuição de EPIS (conforme a demanda), treinamento, atenção médica integral, manutenção de seus instrumentos de trabalho, adaptação do trabalho ao homem e sua participação junto à empresa em decisões relacionadas ao seu trabalho. Merece destaque o fato de vários deles resistirem, mesmo quando disponíveis, ao uso dos equipamentos de proteção.

Uma pesquisa posterior seria conveniente, para determinar as possíveis associações feitas pelos sujeitos dessa necessidade de tato e, portanto, de contato com o lixo e a necessidade inconsciente de punição ligada à culpabilidade, mas, antes de tudo, as relações desses fatos e a realidade social como mantenedora de uma situação de "superego social" (Freud, 1930), que impede "consciência" e a conscientização transformadora. O superego é uma instância interna e inconsciente que, na re-apresentação, pode ser questionado, dependendo da situação do sujeito (Valadares, 1994).

Seria conveniente a introdução de medidas práticas, objetivas e inadiáveis como uma 
coleta seletiva, que separe o lixo reciclável (vidro, lata, madeira, agulha), para evitar acidentes como cortes e ferimentos, dado que o processo de trabalho se estrutura através de uma tecnologia primária, praticamente manual, o que expõe o trabalhador a doenças e acidentes, relacionados ao esforço excessivo exigido pela demanda ocupacional.

Além das medidas de modificação de ambiente físico e de instrumentos de trabalhos, poderiam ser considerados a possibilidade de criação e incentivo a grupos contínuos de encontro de trabalhadores, sem nenhuma obrigação institucional, com a opção de encaminhar, esporadicamente, alguma recomendação ou reivindicação às empresas e à Prefeitura. Esses grupos, formados em cada unidade de coleta e tratamento, e que poderiam se reunir quinzenalmete no horário de trabalho, devem escolher internamente um coordenador e um relator. Um coordenador escolhido "de fora" institucionalizaria o processo e impediria movimentos mais ligados à imaginarização, sempre acolhida no pequeno grupo (Valadares, 1994). Essa prática foi a causa de fracasso de muitas medidas ligadas às comissões de proteção contra acidentes de trabalho. Esse tipo de agrupamento que acolhe toda a sorte de

\section{Referências}

Becker HS 1994. Métodos em Pesquisa em Ciências Sociais. HUITEC, São Paulo.178 pp.

Betancourt OF 1993. La salud ocupacional y los trabajadores de saneamiento ambiental. Salud y Trabajo 13: 3-9.

Cohn A, Karsch US, Hirano S \& Sati AK 1985. Acidente do Trabalho: Uma Forma de Violência. Brasiliense, São Paulo. 158 pp.

Faleiros PVO 1992. Trabalho da Política: Saúde e Segurança dos Trabalhadores. Cortez, São Paulo. 312 pp.

Freud S 1974. Mal Estar na Civilização. (O.C.) 21:75173. 1948. "Das Umbehagen in der Kultur” (1930). G.W. 14: 419-506.

Freud S 1976. A negativa. (O.C.) 19: 290-300. 1948. "Die Verneinung" (1925) G.W. 13: 9-15.

Ilário E 1989. Estudo de morbidade em coletores de lixo de um grande centro urbano. Revista Brasileira de Saúde Ocupacional 17(66): 7-13. manifestação, sem marginalizar, por não estar submetido à hierarquia, tem mais oportunidade de encaminhar sugestões, sem o impedimento de uma censura externa que aciona mecanismos superegoístas sempre internos aos sujeitos. Os encontros podem estar vinculados a alguma atividade de lazer: artesanato, ou cursos de treinamento em atividades artísticas, técnicas, esportivas, etc., sem ligação necessária com o trabalho ou, ainda, outra oportunidade graciosamente oferecida ao trabalhador. Poder-se-ia acompanhar o desenvolvimento de tal atividade, com uma pesquisa sobre melhoria na incidência de doenças, acidentes, satisfação no trabalho, acesso à melhor condição de cidadania, a qual é menos valorizada, pelos indivíduos, do que a condição de sujeito.

Pensamos, assim, que algum trabalho deve ser desenvolvido, no sentido de produzir, entre trabalhadores, um movimento em direção à autonomia, somente conseguido com um encaminhamento de encomendas sociais, ou seja, com o deslocamento contínuo dos ideais, e, portanto, das lideranças. A procura de autonomia é uma das figuras do real, somente manifestadas nos "restos", naquilo que ainda não foi elaborado pelo homem.
Pereira ASO 1978. Acidente de Trabalho em Limpeza Urbana. Vol. 1. COMLURB, Rio de Janeiro. 38 pp.

Robazzi MLCC 1984. Estudo das Condições de Vida, Trabalho e Riscos Ocupacionais a que estão Sujeitos os Coletores de Lixo da Cidade de Ribeirão Preto - Estado de São Paulo. Dissertação de Mestrado. Escola de Enfermagem de Ribeirão Preto, USP, Ribeirão Preto. 120 pp.

Valadares JC 1994. Espaço Ambiente e Situação do Sujeito. Tese de Doutorado. Escola Nacional de Saúde Pública, Fiocruz, Rio de Janeiro. 158 pp.

Velloso MP 1995. Processo de Trabalho da Coleta de Lixo Domiciliar na Cidade do Rio de Janeiro: Percepção e Vivência dos Trabalhadores. Dissertação de Mestrado. Escola Nacional de Saúde Pública, Fiocruz, Rio de Janeiro. 125 pp. 